\title{
Kidney Transplantation in Primary Oxalosis: Data From the EDTA Registry
}

\author{
M. Broyer \\ Hôpital Necker Enfants-Malades, \\ Paris, France \\ F. P. Brunner* \\ Departement für Innere Medizin, \\ Universität Basel, Switzerland \\ H. Brynger \\ Department of Surgery 1, Sahlgrenska \\ Sjukhuset, Göteborg, Sweden \\ S. R. Dykes \\ St Thomas' Hospital, London, United \\ Kingdom \\ J. H. H. Ehrich Medizinische Hochschule Hannover, \\ Federal Republic of Germany
}

\author{
W. Fassbinder Städtische Kliniken Fulda, \\ Federal Republic of Germany \\ W. Geerlings Stichting Thuisdialyse Noord \\ Nederland, Haren, Netherlands \\ G. Rizzoni Ospedale Pediatrico Bambino \\ Gesú, Istituto di Ricerca \\ Scientifica, Roma, Italy \\ N. H. Selwood St Thomas' Hospital, London, \\ United Kingdom \\ G. Tufveson Transplantation Unit, University \\ Hospital, Uppsala, Sweden \\ A. J. Wing St Thomas' Hospital, London, \\ United Kingdom
}

${ }^{*}$ Chairman

\begin{abstract}
This paper reports the results of 98 first kidney transplantations in patients with oxalosis as the primary renal disease as recorded by the EDTA Registry. There were 79 patients who received a cadaveric (CAD) graft and 15 patients with a living related donor (LRD) graft; the type of donor was not recorded for four patients. Initial graft survival appeared to be better after LRD as compared to CAD grafts but at 3 years the poor survival was similar with $23 \%$ for LRD and $17 \%$ for CAD grafts. CAD graft survival did not differ between children and adults and was not affected by the waiting time on dialysis. A slight improvement was observed in grafts performed in the years $1983-1986$ as compared to grafts performed in earlier years. The causes of failure reported were mainly rejection $(33 \%)$ and recurrence of primary renal disease $(31 \%)$. In view of the poor results related to recurrence of

Correspondence and offprint requests to: Professor F. P. Brunner, EDTA Registry, St Thomas' Hospital, London SEl 7EH, UK. Tel: 01-6330636.
\end{abstract}

oxalosis in the graft, the potential of combined kidney and liver transplantation is discussed.

Key words: Primary oxalosis; Kidney transplantation

\section{Introduction}

Primary hyperoxaluria, a synonym for congenital oxalosis, is a rare metabolic disorder caused by accumulation of glyoxylate, which leads to increased synthesis and excretion of glycolate and oxalate. The basic biochemical defect described in 1986 by Danpure and Jennings [1], seems to be the absence of peroxisomal alanine glyoxylate aminotransferase, which is located exclusively in the liver. The disease is characterised clinically by recurrent calcium oxalate kidney stones and nephrocalcinosis resulting in progressive renal insuffciency. Once end-stage renal failure is reached, further calcium oxalate accumulation cannot be prevented by any 
form of dialysis strategy and leads to extrarenal complications with progressive and severely disabling bone disease being the most prominent [2]. Calcification of blood vessels and heart may also occur and cause death [3]. For these reasons, dialysis is quite unsatisfactory and explains why kidney transplantation has been attempted in spite of the almost inevitable recurrence of calcinosis in the graft. Several reports of unsuccessful or successful renal transplantation in patients with primary oxalosis have been published $[4,16]$. Since successful cases may be reported preferentially, and in order to have a more general view on renal transplantation in primary oxalosis, it was decided to analyse the outcome of all such kidney grafts reported to the Registry of the European Dialysis and Transplant Association-European Renal Association (EDTA Registry) up to 31 December 1966.

\section{Methods}

This study is based on information obtained through individual patient questionnaires that have been collected each year since 1965 by the EDTA Registry. The essential structure of the patient questionnaire has remained largely unchanged since 1971 [17]. The coding structure for primary renal diseases was altered in 1973, at which time code 53 was introduced for 'oxalosis'. The definition of code 53 was modified in 1985 to 'primary oxalosis', in order to exclude the rare forms of end-stage renal failure due to secondary hyperoxaluria. Since restricting the study to those cases registered since 1985 would result in too few cases for study, it was felt reasonable to include all cases of oxalosis reported to the Registry. Secondary oxalosis is known to occur more commonly in the older age groups, carries a better prognosis than primary oxalosis, and is also uncommon. For this reason, studying all cases of oxalosis was considered unlikely to affect the results adversely. The method of calculating actuarial survival using life table methods has been previously described [18].

\section{Results}

There were 221 patients reported to the Registry up to 31 December 1986 with oxalosis recorded as the primary renal disease: 121 males, 99 females and one with the sex not recorded. The age distribution at start of treatment is given in Fig. 1. Figure 2 shows the age distribution of 79 patients at the time of receiving their first cadaveric graft. Sixty per cent of these graft recipients were younger than 25 . The number of new patients accepted for renal replacement therapy per year varied from 9 to 22 in the last 10 years. The number of grafts performed yearly seemed to increase slightly from 1976 to 1986 (Fig. 3).

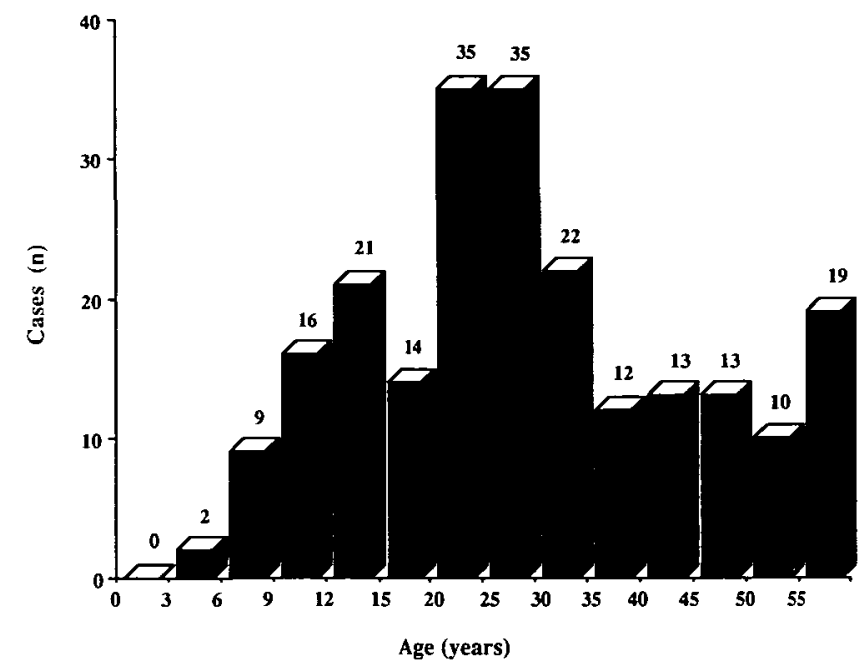

Fig. 1. Age distribution at start of renal replacement therapy of 221 patients with oxalosis.

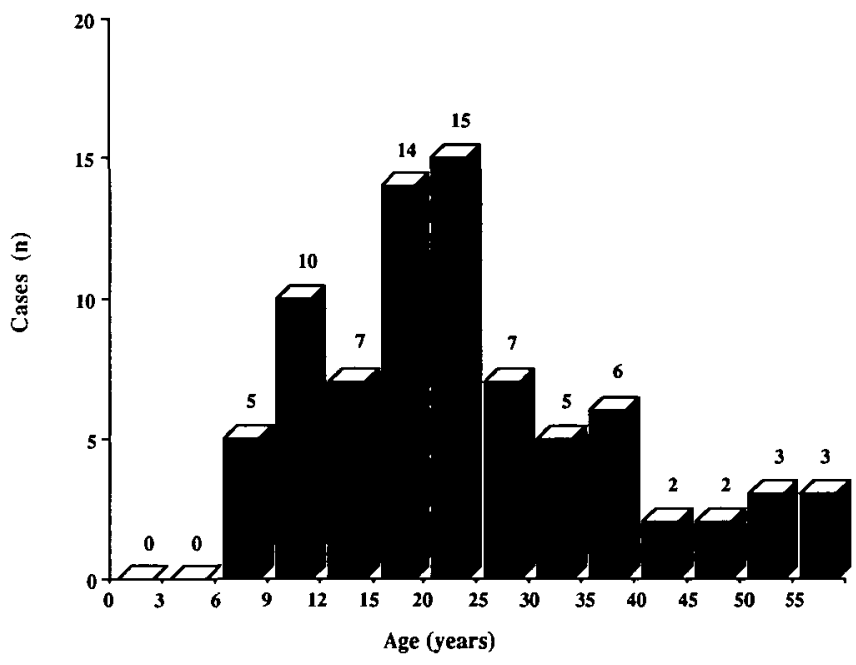

Fig. 2. Age distribution at first cadaveric graft of patients with oxalosis.

Of a total of 98 patients who received a first transplant ( 79 cadaveric, 15 living donor and 4 where the source was not recorded), $76 \%$ were performed since 1980 and $58 \%$ since 1983 . The waiting time on dialysis before grafting was variable; five patients were grafted directly without dialysis, 35 were grafted within the first year, 21 within the second year and 36 after a longer interval. In one case, the treatment history prior to transplantation had not been reported to the Registry.

Graft survival, shown in Table 1 and Fig. 4, appeared to be better initially after living related as compared to cadaveric grafting, but this was not sustained. Primary non-function was recorded for $11 \%$ of first cadaveric grafts. Cadaver graft survival was no different in children compared to adults (Fig. 5) and no living donor graft was performed in patients under the age of 15 . Graft survival 


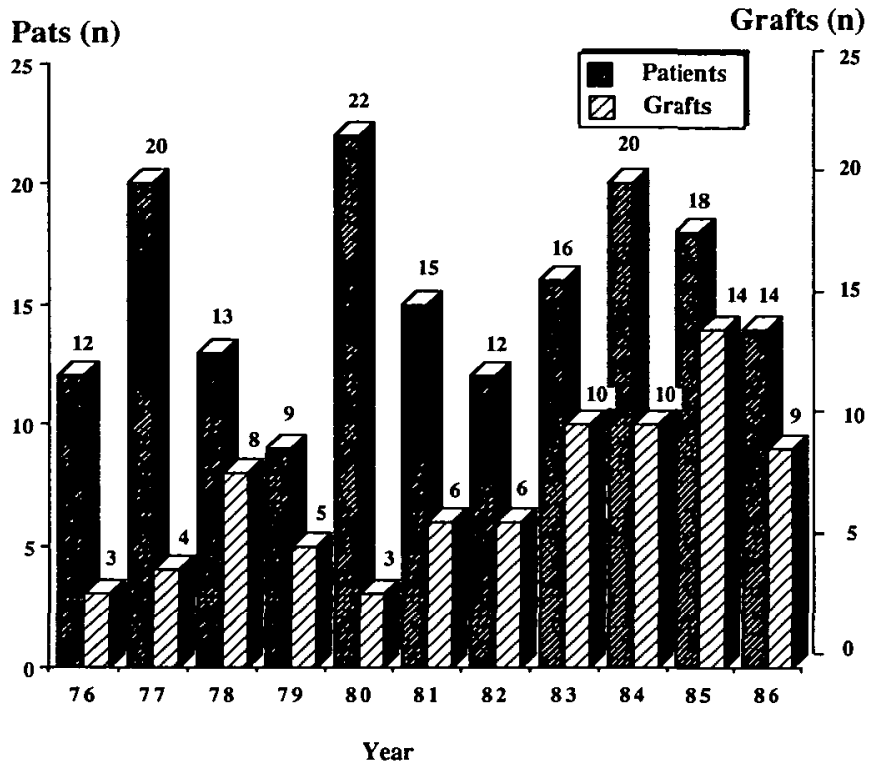

Fig. 3. Number of patients starting renal replacement therapy and number of grafts in patients with oxalosis by year.

Table 1. First cadaveric graft survival in patients with oxalosis $(n=79)$

\begin{tabular}{llrrr}
\hline & \multicolumn{3}{l}{ Months } & \\
\cline { 2 - 5 } & $0-6$ & $7-12$ & $13-24$ & $25-26$ \\
\hline Interval $n$ at risk & 77 & 28 & 20 & 15 \\
Interval $n$ failed & 42 & 5 & 2 & 6 \\
Cumulative survival (\%) & 45 & 32 & 29 & 17 \\
\hline
\end{tabular}

Graft Survival (\%)

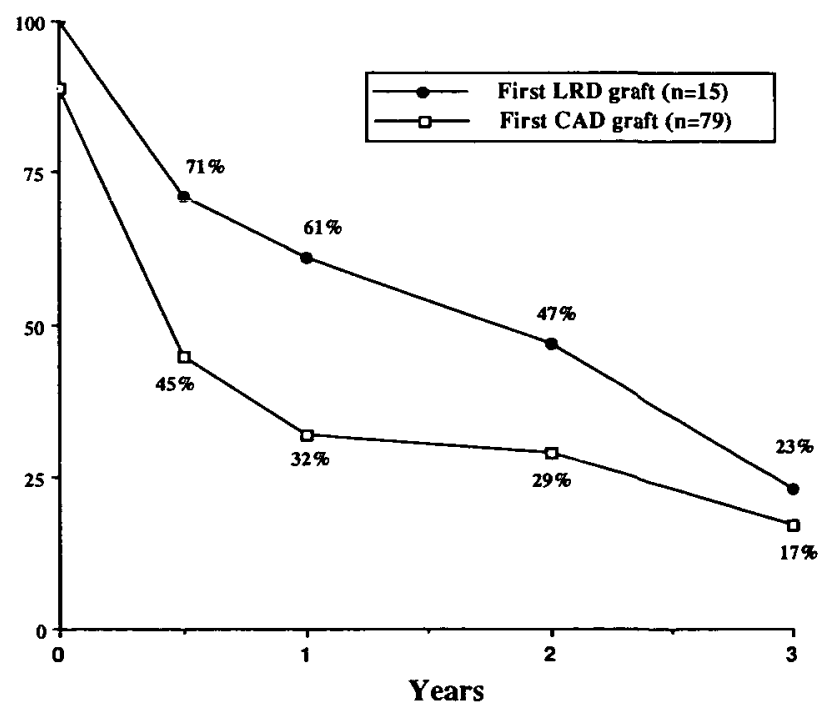

Fig. 4. First graft actuarial survival according to source of graft. Primary non-function was recorded for $11 \%$ of CAD grafts.

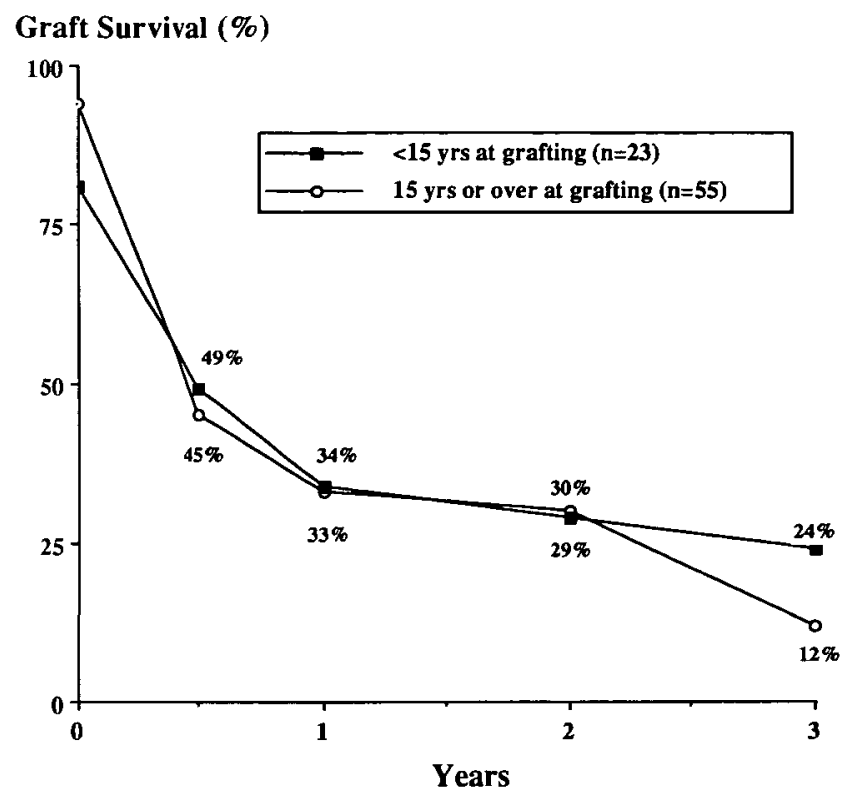

Fig. 5. First cadaver graft survival according to age of patient at grafting.

\section{Graft Survival (\%)}

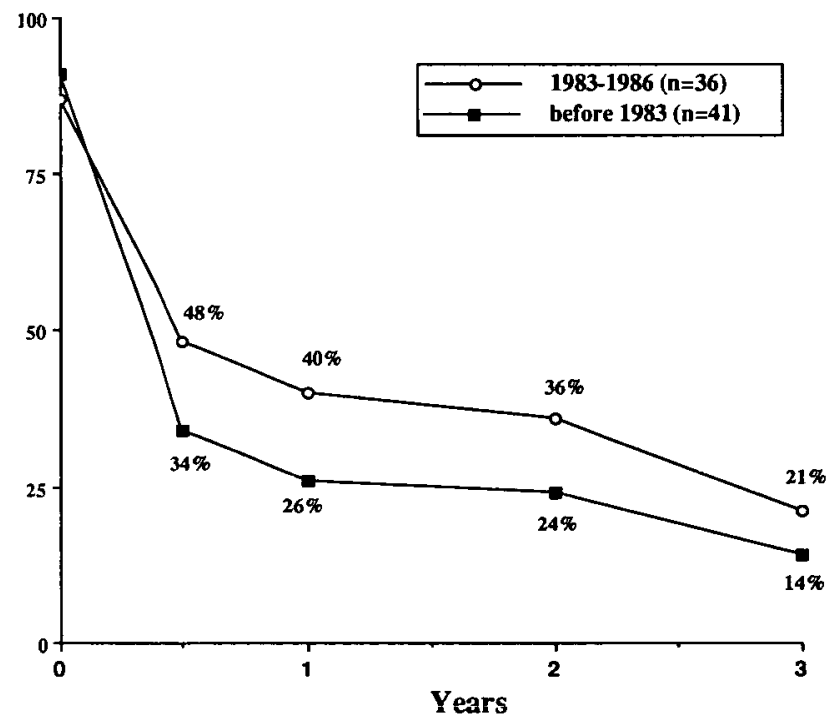

Fig. 6. First cadaver graft survival according to year of grafting

was slightly better for transplants performed more recently, that is between January 1983 and December 1986 (Fig. 6), in keeping with improving graft survival for other primary renal diseases $[19,20]$. Graft survival was also computed according to waiting time on dialysis: no difference was found between patients grafted within or after the first year of starting treatment (Fig. 7).

Of the first grafts that failed, $88 \%$ did so within the first year. Among the causes reported for these, only $33 \%$ were related to rejection compared to $70 \%-85 \%$ in patients with other primary renal diseases [21]. Recurrence of 


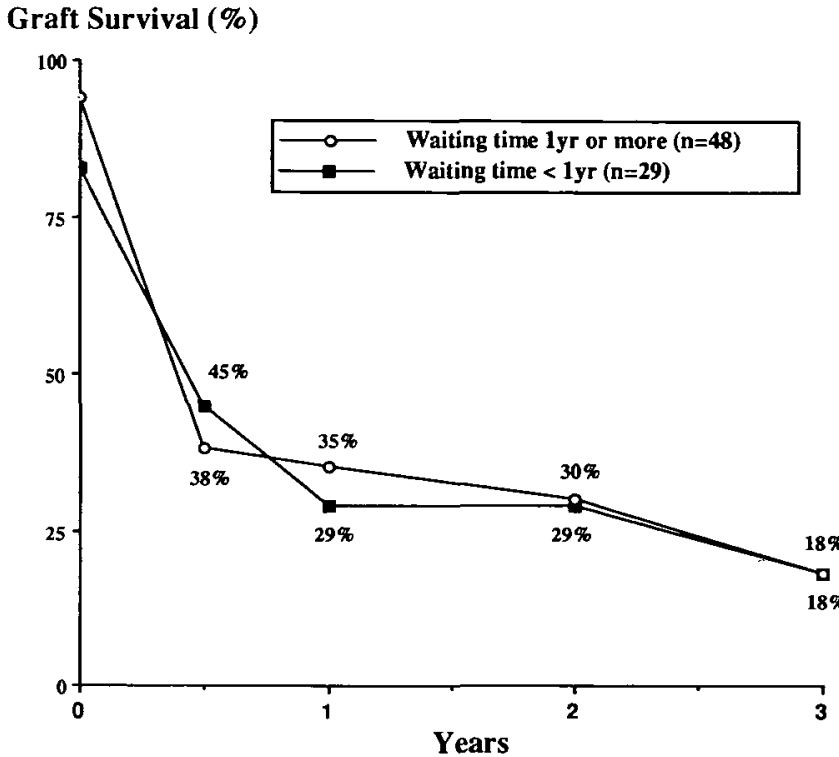

Fig. 7. First cadaver graft survival according to time on dialysis prior to transplantation

oxalosis in the graft was recorded as the cause of graft failure in $31 \%$. These proportions were similar for the eight second graft failures.

Patient survival after grafting in 1980-1986 and for all patients with oxalosis starting renal replacement therapy during the same period is shown in Table 2. Despite the high graft failure rate, mortality appeared to be similar, or only slightly higher, after grafting. This resulted in a cumulative actuarial survival of $74 \%$ at 3 years after receiving a first cadaver or living donor graft. Actuarial survival, irrespective of the mode or renal replacement therapy, was $79 \%$ at 3 years. This compares unfavourable to patients with the common primary renal diseases of similar age distribution, who were found to have a 5-year cumulative survival above $80 \%$ [19].

Table 2. Per cent actuarial patient survival $1980-1986$

\begin{tabular}{llll}
\hline & \multicolumn{3}{l}{ Year } \\
\cline { 2 - 4 } & 1 & 2 & 3 \\
\hline After first graft $(n=60)$ & 85 & 85 & 74 \\
On RRT (including grafting $n=122)$ & 91 & 87 & 79 \\
\hline
\end{tabular}

The distribution of the main causes of death was studied and the results are shown in Table 3 according to whether the patient had ever received a transplant. There were slightly less than twice as many deaths in ungrafted than grafted patients. Cardiovascular causes were the most frequent $(51 \%)$ with infection second $(14 \%)$. Deaths from infection were rarely recorded in ungrafted patients.
Table 3. Per cent distribution of causes of death according to whether or not the patient had ever received a transplant

\begin{tabular}{llllll}
\hline & Cardiac & Vascular & Infection & $\begin{array}{l}\text { Therapy } \\
\text { ceased }\end{array}$ & Other \\
\hline $\begin{array}{c}\text { Ungrafted (\%) } \\
(n=69)\end{array}$ & 41 & 16 & 4 & 6 & 33 \\
$\begin{array}{c}\text { Grafted (\%) } \\
(n=39)\end{array}$ & 36 & 5 & 31 & 3 & 25 \\
$\begin{array}{c}\text { All }(\%) \\
(n=108)\end{array}$ & 39 & 12 & 14 & 5 & 31 \\
\hline
\end{tabular}

Cardiovascular causes, on the other hand, were more frequent $(57 \%)$ in ungrafted patients than in those who had received a transplant at some time $(41 \%)$.

\section{Discussion}

Historically, renal transplantation was considered as contraindicated in primary hyperoxaluria $[4,5]$. This attitude was confirmed by several reports which recorded poor graft survival due to oxalate deposition in the transplanted kidney $[6,10]$. Nevertheless, there were some publications reporting a single or a small number of successful kidney transplants $[11,15]$. These reports stressed the importance of specific measures such as intensive dialysis at time of grafting, and pyridoxine administration, which may decrease oxalate deposition in the graft. The largest series with well-defined prophylactic medical treatment was reported in 1984 by Scheinmann et al [16]. It included ten living related donor transplants, of whom seven had a functioning graft 1-7 years later, and one cadaver graft that lasted for 9 years. Considered together with the poor prognosis of patients with primary oxaluria on any form of dialysis therapy, these limited but rather optimistic reports probably encouraged continued attempts with kidney transplantation in patients with primary oxalosis, since the number of grafts per year recorded in the EDTA Registry increased between 1982 and 1986.

This report confirms the poor prognosis of kidney transplantation in patients recorded by the EDTA Registry with the diagnosis of oxalosis, although it is important to keep in mind that, before 1985, some patients with secondary oxalosis may have been registered under the same code. Since secondary oxalosis is either related to acute but transient oxalate intoxication or to uncontrolled, though in principle controllable, enteric hyperabsorption of oxalate, kidney transplantation for secondary oxalosis is likely to have a much better prognosis. Thus, the low graft survival rates reported here might still overestimate the true situation concerning primary hyperoxaluria. 
Recipients of living related donor transplants run a lower risk of oliguria due to ischaemic damage at transplantation or due to rejection episodes. It is not surprising, therefore, that fewer living related donor grafts were lost during the early post-transplant months. However, their failure rate was higher thereafter and resulted in a graft survival that was as low at 3 years as in cadaveric grafts (Fig. 4).

End-stage renal failure occurring in childhood might point to a more severe form of oxalosis. However, graft survival was no better in adults than in children, indicating that once on dialysis the oxalate pool size would probably have the same potentially deleterious effect on the graft. This is also reflected by similarly poor graft survival irrespective of the waiting time on dialysis (Fig. 7). Finally it is also disappointing to note only a slight improvement of graft survival due to fewer early failures but with a similar late failure rate in more recent years. The poor prognosis of kidney transplantation in patients with primary hyperoxaluria may lend support to another approach, namely combined hepatic and renal transplantation [22]. Whether or not correction of the underlying metabolic disorder by this approach will improve the outlook for patients with primary oxalosis remains yet to be clearly demonstrated.

Acknowledgements. The work of the EDTA Registry has been supported by grants from governments or national societies for nephrology. Grants have also been made by the AKZO Group (Fibres and Polymers Division), Asahi Medical Co. Ltd, B. Braun Melsungen AG, Baxter Healthcare Corporation, Bellco SpA, Boehringer Mannheim GmbH, CD Medical International Ltd, Cilag AG Research, Fresenius Ltd, Gambro AB, Hospal Ltd, and Sandoz AG.

We thank all those doctors and their staff who have kindly completed EDTA Registry questionnaires.

\section{References}

1. Danpure CJ, Jennings PR. Peroxisomal alanine: glyoxylate aminotransferase deficiency in primary hyperoxaluria type I. FEBS Letters 1986; 201: 20-24

2. Broyer M, Gagnadoux MF. L'oxalose: aspects cliniques et évolutifs. In Legrain M, Kuss J, eds. Séminaire D'Uro-Néphrologie. Masson Publishers, Paris. 1975: 136-146
3. Blackburn WE, McRoberts JW, Bhathena D et al. Severe vascular complications in oxalosis after bilateral nephrectomy. Ann Intern Med 1975; 82: 44-46

4. Deoohar DS, Tung KS, Zuhle V et al. Kidney transplantation in primary oxalis. Clin Nephrol 1976; 5: 239-244

5. Klauwers $\mathbf{J}$, Wolf PL, Cohn R. Failure of renal transplantation in primary oxalosis. $J A M A$ 1969; 209: 551

6. Wilson, RE. Renal transplantation in congenital and metabolic diseases. JAMA 1975; 232: 148-153

7. Saxon A, Busch GJ, Merrill JP et al. Renal transplantation in primary hyperoxaluria. Arch Intern Med 1974; 133:464 467

8. Halverstadt DB, Wenzl JE. Primary hyperoxaluria and renal transplantation. J Urol 1974; 111: 398-402

9. Jacobs C, Rottenburg J, Reach I. Terminal renal failure due to oxalosis in 14 patients. Proc Eur Dial Transplant Assoc 1974; 11 : 359-366

10. Novik AL, Braun WE, Magnusson M, Stowe N. Current status of renal transplantation at the Cleveland clinic. J Urol 1979; 122 : 433-437

11. O'Regan P, Constable AR, Joekes AM et al. Successful renal transplantation in primary hyperoxaluria. Postgrad MedJ 1980; 56: 288-293

12. Bohannon LL, Norman DJ, Barry J, Bennett W. Cadaveric renal transplantation in a patient with primary hyperoxlauria. Transplantation 1983; 36: 114-115

13. David D, Cheigh JS, Stenzel KH, Rubin AL. Successful renal transplantation in a patient with primary hyperoxaluria. Transplantation Proc 1983; 15: 2168-2171

14. Breed A, Chesney $\mathbf{R}$, Friedman $\mathrm{A}$ et al. Oxalosis induced bone disease: a complication of transplantation and prolonged survival in primary oxalosis. Report of a case. J Bone Joint Surg 1981; 63A: $310-316$

15. Whelchel JD, Alion DV, Luke J et al. Successful renal transplantation in hyperoxaluria. Transplantation 1983; 35: 161-164

16. Scheinmann JI, Najarian JS, Mauer M. Successful strategies in renal transplantation in primary oxalosis. Kidney Int 1984; 25: 804-81 1

17. Bryoer M, Brunner FP, Brynger $\mathrm{H}$ et al. Demography of dialysis and transplantation in Europe 1984. Nephrol Dial Transplant 1986; 1: $1-8$

18. Kramer P, Broyer M, Brunner FP et al. Combined report on regular dialysis and transplantation in Europe, XIV, 1983. Proc EDTA-ERA 1985; 21:2-68

19. Brunner FP, Broyer M, Brynger $\mathrm{H}$ et al. Survival on renal replacement therapy: data from the EDTA Registry. Nephrol Dial Transplant 1988; 2: 109-122

20. Geerlings $W$, Tufveson $G$, Broyer $M$ et al. Combined report on regular dialysis and transplantation in Europe, XVII, 1986. Proc EDTA-ERA 1980

21. Wing AJ, Broyer M, Brunner FP et al. Combined report on regular dialysis and transplantation in Europe, XIII, 1982. Proc EDTA-ERA 1983; 20:2-75

22. Watts RWE, Rolles K, Morgan SH, Williams R, Calne RY et al. Successful treatment of primary hyperoxaluria type I by combined hepatic and renal transplantation. Lancet 1987; 2: 474-475

Received for publication 20.10.89

Accepted 7.2 .90 